\title{
Relationship between load/unload response ratio and damage variable and its application
}

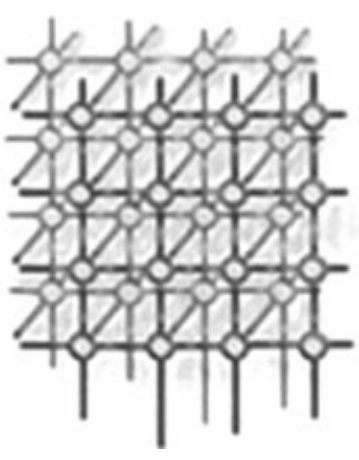

Lang-Ping Zhang ${ }^{1,2, *, \dagger}$, Xiang-Chu Yin ${ }^{1,2}$ and Nai-Gang Liang ${ }^{2}$

${ }^{1}$ Institute of Earthquake Science, China Earthquake Administration, Beijing 100036, China

${ }^{2}$ State Key Laboratory of Nonlinear Mechanics, Institute of Mechanics, Chinese Academy of Sciences, Beijing 100190, China

\section{SUMMARY}

The physics-based parameter: load/unload response ratio (LURR) was proposed to measure the proximity of a strong earthquake, which achieved good results in earthquake prediction. As LURR can be used to describe the damage degree of the focal media qualitatively, there must be a relationship between LURR and damage variable $(D)$ which describes damaged materials quantitatively in damage mechanics. Hence, based on damage mechanics and LURR theory, taking Weibull distribution as the probability distribution function, the relationship between LURR and $D$ is set up and analyzed. This relationship directs LURR applied in damage analysis of materials quantitatively from being qualitative earlier, which not only provides the LURR method with a more solid basis in physics, but may also give a new approach to the damage evaluation of big scale structures and prediction of engineering catastrophic failure. Copyright (c) 2009 John Wiley \& Sons, Ltd.

Received 30 September 2008; Accepted 24 July 2009

KEY WORDS: damage variable $(D)$; load/unload response ratio (LURR); earthquake prediction; damage evaluation

\footnotetext{
${ }^{*}$ Correspondence to: Lang-Ping Zhang, Institute of Earthquake Science, China Earthquake Administration, No. 63, Fuxing Road, Haidian District, Beijing 100036, China.

†E-mail: zhanglp@lnm.imech.ac.cn
}

Contract/grant sponsor: Special Funds for Major State Basic Research Programs; contract/grant number: $2004 \mathrm{CB} 418406$ Contract/grant sponsor: NSFC; contract/grant numbers: 40704007, 10721202

Contract/grant sponsor: Ministry of Science and Technology of China; contract/grant number: 2005DKA64003

Copyright @ 2009 John Wiley \& Sons, Ltd. 


\section{BRIEF INTRODUCTION OF LURR}

From the macroscopic viewpoint, the stress-strain curve is a comprehensive description of the mechanical behaviors of materials. A typical stress-strain curve for focal media (rock) is shown in Figure 1. If the load acting on the material increases monotonously, the material will experience the regimes of elastic, damage process and failure or destabilization. The most essential characteristic of the elastic regime is its reversibility, namely that the positive process and the contrary process are reversible. In other words, the loading and the unloading modulus are equal to each other. Contrary to the elastic regime, the damage regime is irreversible and the unloading response is different from the loading one, that is, the loading modulus is different from the unloading one. This difference indicates the deterioration of the material due to damage, which also means that the parameter LURR can describe the damage degree of materials qualitatively.

Based on earthquake mechanics, fracture mechanics, damage mechanics, and nonlinear sciences, Yin Xiangchu has proposed an approach called LURR to earthquake prediction and after several years' practice, some success in earthquake prediction has been achieved $[1,2]$.

In order to measure the difference between load response and unload one quantitatively, two parameters are defined as follows.

The first one is the response rate $X$ defined as

$$
X=\lim _{\Delta P \rightarrow 0} \frac{\Delta R}{\Delta P}
$$

where $\Delta P$ and $\Delta R$ denote the increments of load $P$ and response $R$, respectively.

The second one is load/unload response ratio (LURR) (denoted as $Y$ ) defined as

$$
Y=X_{+} / X_{-}
$$

where $X_{+}$and $X_{-}$refer to response rate under loading and unloading condition, respectively.

If we take the strain as the response to the loaded or unloaded stress on the rock material, from Figure 1, it is clear that $Y=1$ when the material is in the elastic regime since $X_{+}=X_{-}$. In the damaged regime where $X_{+}>X_{-}, Y>1$. The more severely the material is damaged, the larger the

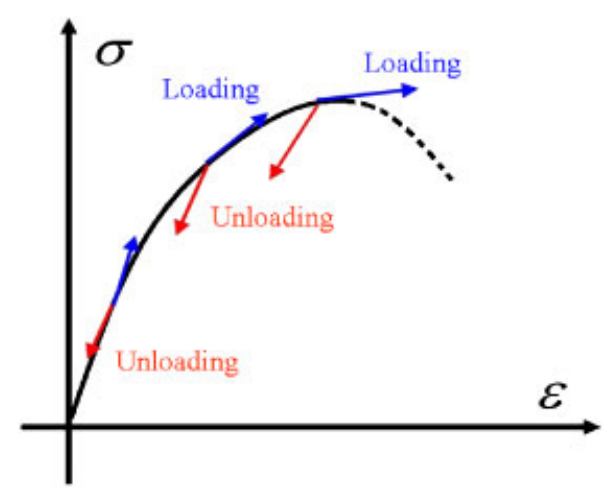

Figure 1. The stress-strain curve of rock. 
$Y$ value will be. As the media approaches failure, the $Y$ value becomes larger and larger. Therefore, the LURR value $(Y)$ could measure the damage of the seismogenic region qualitatively, describe the proximity to failure and also act as a precursor for the earthquake prediction/forecasting.

In actual earthquake prediction, the LURR value $Y$ is defined directly through the ratio of released seismic energy in the loading and unloading periods as follows:

$$
Y=\frac{\left(\sum_{i=1}^{N_{+}} E_{i}^{m}\right)_{+}}{\left(\sum_{i=1}^{N_{-}} E_{i}^{m}\right)_{-}}
$$

where $E$ denotes released seismic energy, the ' + ' sign means loading and ' - ' sign means unloading, $m=0, \frac{1}{3}, \frac{1}{2}, \frac{2}{3}$ or 1 . When $m=1, E^{m}$ is exactly the energy itself; $m=\frac{1}{2}, E^{m}$ denotes the

Benioff strain; $m=\frac{1}{3}$ and $\frac{2}{3}, E^{m}$ represents the linear scale and area scale of the seismogenic zone, respectively; $m=0, Y$ is equal to $N_{+} / N_{-}$, where $N_{+}$and $N_{-}$denote the number of earthquakes which occurred during the loading and unloading duration, respectively. In this paper $m$ is adopted as $\frac{1}{2}$, which means that $Y$ is determined by Benioff strain during the loading duration over the unloading one.

The retrospective inspections of hundreds of earthquake cases have validated the LURR [3-6]. For more than $80 \%$ of the examined cases the $Y$ value fluctuates around 1 during the early stage of the seismogenic process and it rises when the region approaches the onset of a strong earthquake. Then $Y$ reaches its maximum (significantly larger than 1), but decreases sharply on the eve of the main shock.

After several years of practice in earthquake prediction, the forecasting effect of LURR has been improved obviously and applied in China mainland, West America, Japan, Australia, Italy, Iran, etc. $[7,8]$. At the same time, the LURR method has also been deeply studied in physics, laboratory studies, and numerical simulations [9-12]. Besides earthquake prediction, this method has been used in other fields such as slopes stability [13] and landslides [14,15].

\section{RELATIONSHIP BETWEEN LURR AND $D$}

Damage mechanics is a branch of solid mechanics. Kachanov [16] proposed to describe the collective effect of the deterioration by a field variable continuously, which is called damage variable $(D)$. As we know, the LURR value can be used to measure the damage degree of the seismogenic region qualitatively. Hence, there must be a relationship between LURR and $D$. It will be the main topic discussed in this part. In this part, the relationship between LURR and $D$ is set up and analyzed with the Weibull distribution as the probability distribution function and then the acoustic emission (AE) experiment is presented and the analysis of the experiment results validates the relationship.

\section{A new definition of LURR}

In the case of uniaxial tension or compression, it can be proved that a close relationship between LURR and $D$ exists. 
First, let us introduce the actual stress $\sigma_{\mathrm{a}}[16,17]$

$$
\sigma_{\mathrm{n}}=\sigma_{\mathrm{a}}(1-D)
$$

where $\sigma_{\mathrm{n}}$ is the nominal stress, $\sigma_{\mathrm{a}}$ is the actual stress, $D$ is the damage variable. Then the total differential of $\sigma_{\mathrm{n}}$ is

$$
\mathrm{d} \sigma_{\mathrm{n}}=\mathrm{d} \sigma_{\mathrm{a}}(1-D)-\sigma_{\mathrm{a}} \mathrm{d} D
$$

We assume $\mathrm{d} D=0$ when the material is under unloading state; hence,

$$
\begin{aligned}
& \mathrm{d} \sigma_{\mathrm{n}(+)}=\mathrm{d} \sigma_{\mathrm{a}(+)}(1-D)-\sigma_{\mathrm{a}} \mathrm{d} D \\
& \mathrm{~d} \sigma_{\mathrm{n}(-)}=\mathrm{d} \sigma_{\mathrm{a}(-)}(1-D)
\end{aligned}
$$

where the sign ' + ' means loading and the sign ' - ' means unloading.

According to the Hooke law

$$
\begin{aligned}
& \mathrm{d} \sigma_{\mathrm{a}(+)}=E_{0} \mathrm{~d} \varepsilon_{(+)} \\
& \mathrm{d} \sigma_{\mathrm{a}(-)}=E_{0} \mathrm{~d} \varepsilon_{(-)}
\end{aligned}
$$

where $E_{0}$ is the initial Young's modulus.

From Equations (6) and (7), the loading and the unloading responses can be expressed as below, respectively,

$$
\begin{aligned}
& X_{+}=\frac{\mathrm{d} \varepsilon_{(+)}}{\mathrm{d} \sigma_{\mathrm{n}(+)}}=\left(E_{0}(1-D)-\frac{\sigma_{\mathrm{a}} \mathrm{d} D}{\mathrm{~d} \varepsilon_{(+)}}\right)^{-1} \\
& X_{-}=\frac{\mathrm{d} \varepsilon_{(-)}}{\mathrm{d} \sigma_{\mathrm{n}(-)}}=\left(E_{0}(1-D)\right)^{-1}
\end{aligned}
$$

From the definition of the LURR (Equation (2)), it can be calculated as

$$
Y_{E}=\frac{X_{+}}{X_{-}}=\frac{1}{1-\frac{\varepsilon}{(1-D)} \frac{\mathrm{d} D}{\mathrm{~d} \varepsilon_{(+)}}}
$$

which is the new definition of LURR with damage variable $(D)$ and strain as response.

Taking strain as input, based on the damage model proposed by Lyakhovsky [18,19], the damage evolution in case of one-dimensional deformation can be calculated in terms of the following equation [20]:

$$
\frac{\mathrm{d} D}{\mathrm{~d} t}=C_{1} E_{0}\left(\varepsilon^{2}-\varepsilon_{\mathrm{cr}}^{2}\right)
$$

where $C_{1}$ is a positive parameter in the model to be material property and describes the rate of damage evolution for a given deformation; $E_{0}$ is the initial Young's modulus and $\varepsilon_{\mathrm{cr}}$ is the critical strain that corresponds to a neutral state between healing and degradation of the material, but the healing phenomena will not be considered in this text. If the damage and strain are both given, the new LURR value can be calculated by using Equation (9). 


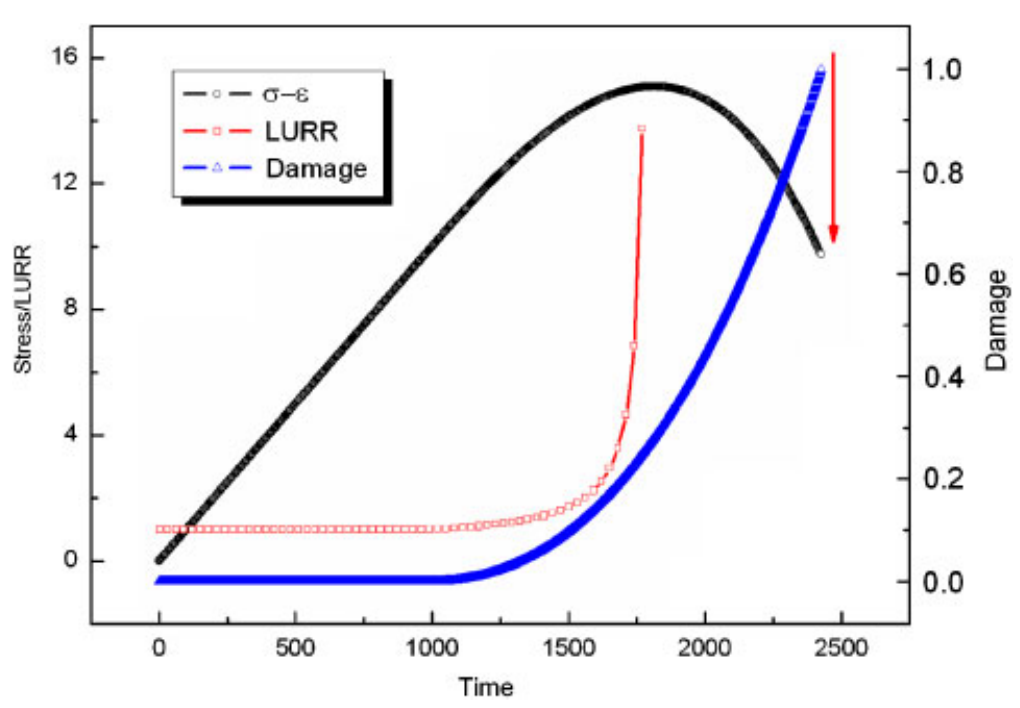

Figure 2. The damage and the new LURR evolution curves, stress-strain curve when taking linearly increasing strain as input data.

Taking the linearly increasing strain as input data, the damage and the new LURR evolution, the nominal stress-strain curves are shown in Figure 2. It is clear that the LURR value reaches the peak value when the nominal stress attains the maximum. Hence, the LURR peak value could be a good predictor for the catastrophic failure of the material.

\section{Relationship between LURR and $D$}

Based on statistical mesoscopic damage mechanics, a statistical model of heterogeneous elasticbrittle materials was proposed [21,22]. It is assumed that such a sample consists of linear elastic but brittle units, namely that all units have the same elastic modulus but different breaking stress threshold.

Suppose that the material follows a probability distribution function $h\left(\varepsilon_{\mathrm{c}}\right)$ in the mesoscopic level, such as the Weibull distribution [23,24]:

$$
h\left(\varepsilon_{\mathrm{c}}\right)=m \varepsilon_{\mathrm{c}}^{m-1} \exp \left(-\varepsilon_{\mathrm{c}}^{m}\right)
$$

where $m$ is the Weibull modulus. Hence, the damage function about strain is:

$$
D(\varepsilon)=\int_{0}^{\varepsilon} h\left(\varepsilon_{\mathrm{c}}\right) \mathrm{d} \varepsilon_{\mathrm{c}}=1-\mathrm{e}^{-\varepsilon^{m}}
$$

Substituting Equation (12) into Equation (9),

$$
Y_{E}=\frac{1}{1-m \varepsilon^{m}}=\frac{1}{m\left(\varepsilon_{\mathrm{F}}^{m}-\varepsilon^{m}\right)}
$$




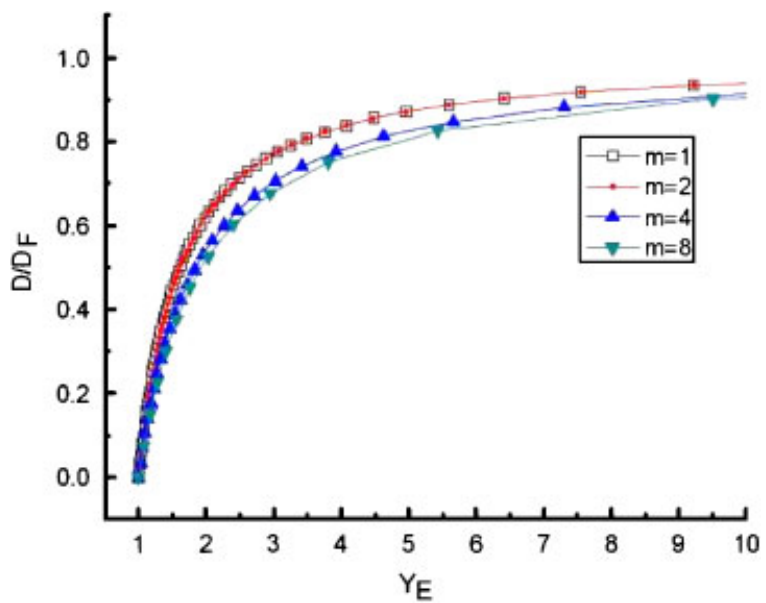

Figure 3. The curves of the relationship between $D / D_{\mathrm{F}}$ and $Y_{E}$, where $D_{\mathrm{F}}=1-\mathrm{e}^{-(1 / m)}$ is the damage value when the material is failed.

is obtained. Here $\varepsilon_{\mathrm{F}}=(1 / m)^{1 / m}$ is the strain at the failure point. Substituting $\varepsilon_{\mathrm{F}}=(1 / m)^{1 / m}$ to Equation (12), the damage degree at the failure point is $D_{\mathrm{F}}=1-e^{-1 / m}$. From Equations (12) and (13), we can get

$$
Y_{E}=\frac{1}{1-m \varepsilon^{m}}=\frac{1}{1+m \ln (1-D(\varepsilon))}
$$

as the relationship between damage variable $(D)$ and LURR $(Y)$. When the Weibull modulus $m=1,2,4,8$, the relationships between $D / D_{\mathrm{F}}$ and $Y_{E}$ are shown in Figure 3 .

\section{Experimental analysis}

Our group has carried out AE experiments for medium scale rock specimens by means of international cooperation [10,25-28]. The dimensions of the specimens are $300 \mathrm{~mm} \times 360 \mathrm{~mm} \times 25 \mathrm{~mm}$. The experiments were conducted using MTS-100 servo-control experimental equipment in the Institute of Geophysics, China Seismological Bureau. The maximum load for this facility is 100 ton in the axial direction and 10 ton in the lateral direction. Boundary-displacement control is used to load the system until final failure. The samples are subjected to both axial stress $\sigma_{1}$ and lateral load $\sigma_{2}$ simultaneously and another principle stress $\sigma_{3}$ is zero. The greatest, intermediate and least principle stress are $\sigma_{1}, \sigma_{2}, \sigma_{3}$, respectively, and $\sigma_{1} \neq \sigma_{2} \neq \sigma_{3}$. Therefore, the stress state is a tri-axial stress state (in Figure 4). In our experiments the lateral stress $\sigma_{2}$ keeps constant until the samples fracture, and the axial stress $\sigma_{1}$ consists of two parts: the constant loading rate of tectonic stress build-up and a sinusoidal stress perturbation, which simulates the periodic loading and unloading cycles induced by tidal forces. The size of the rock specimens and the arrangement of the AE sensor are shown in Figure 4, while the loading process and AE event rate and energy rate versus time for the specimen are shown in Figure 5. The evolution of LURR during the rock fracture experiment has been analyzed in terms of Equation (3), AER (Accelerating Energy Release) before macro-fracture 


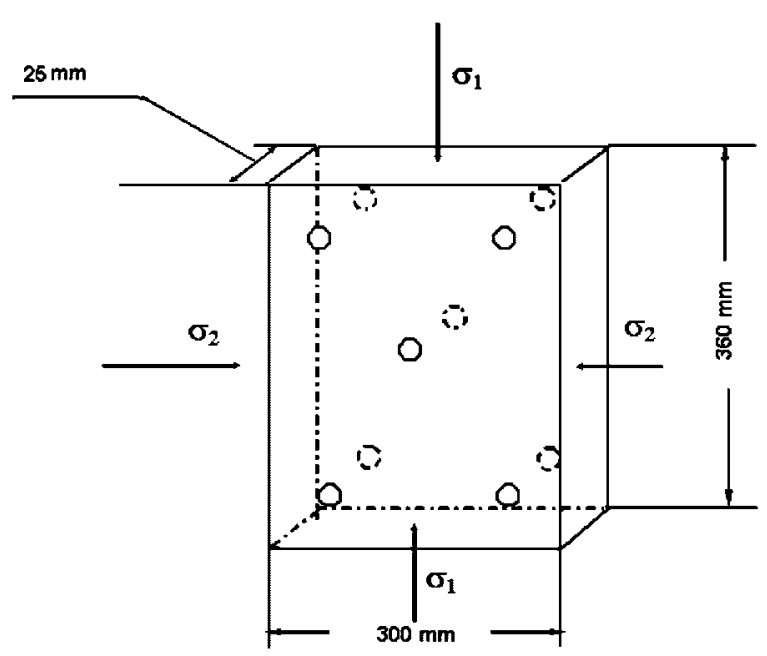

Figure 4. The Geometry of the specimens, the loading conditions, and the arrangement of AE sensors (circles).

of the samples and the correlationship between the AE and the load are also studied by Zhang [25-28]. Figure 6 shows the curve of LURR value versus time during rock fracture experiment for the specimen in terms of Equation (3).

Now, let us analyze the experimental results of the aforementioned system. Early in the 1960s, a kind of statistical description of micro cracks (i.e. number density of micro cracks) was proposed for the evolution of damage [29-31]. We will also take the statistical method to describe the damage degree of the material. Suppose the damage degree is $D_{\mathrm{F}}$ when the media gets failed, then the damage degree at time $t$ can be calculated as

$$
\frac{D(t)}{D_{\mathrm{F}}}=\frac{\int_{0}^{t}[E(t)]^{m} \mathrm{~d} t}{\int_{0}^{T}[E(t)]^{m} \mathrm{~d} t}
$$

where $D(t)$ is the damage degree at time $t, T$ is the total experimental time, $[E(t)]^{m}$ denotes the AE rate at time $t$, when $m=0,[E(t)]^{m}$ means the AE event rate, when $m=1,[E(t)]^{m}$ means the AE energy rate, and when $m=\frac{1}{2},[E(t)]^{m}$ means the square root of the AE energy, that is, Benioff strain rate. Hence, the damage evolution of the rock specimen can be investigated in terms of Equation (15). The curves of the damage evolution and stress-strain are shown in Figures 7 and 8 , respectively.

Zhang has analyzed the experimental data in terms of Equation (3) with Benioff strain as response rate by using the LURR method (Figure 6) [27,28]. We have got a new LURR formula with damage and strain as response in Equation (9) and the data of damage and strain of the experiment are given in Figures 7 and 8 respectively, hence, the new LURR value can be calculated and shown in Figure 9.

In Figure 9, when $t=12000 \mathrm{~s}$, the LURR value attained the maximum (much greater than 1), and then decreased sharply on the eve of the fracture. The dashed line visually indicates the trend of 


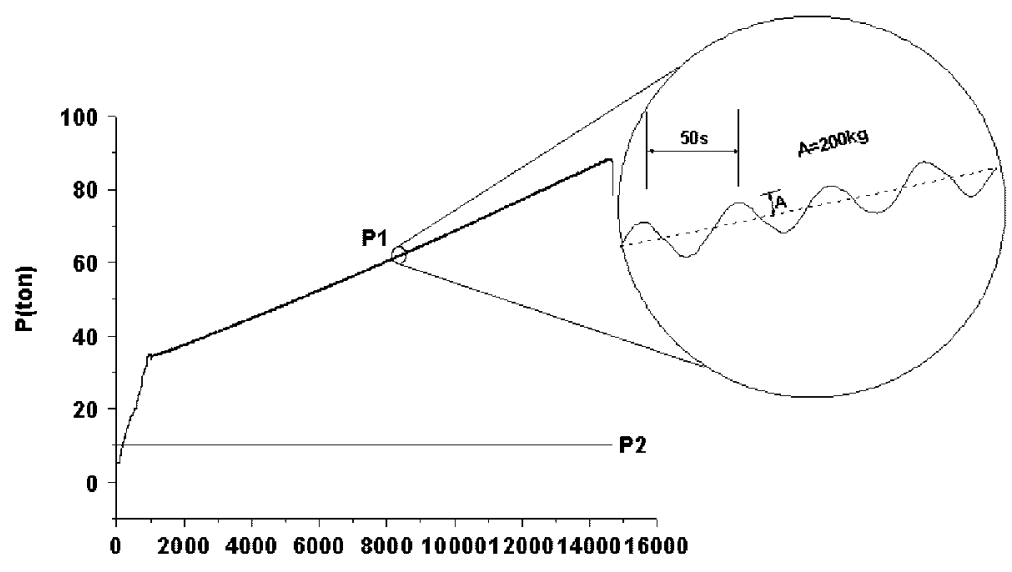

(a)

T[s]
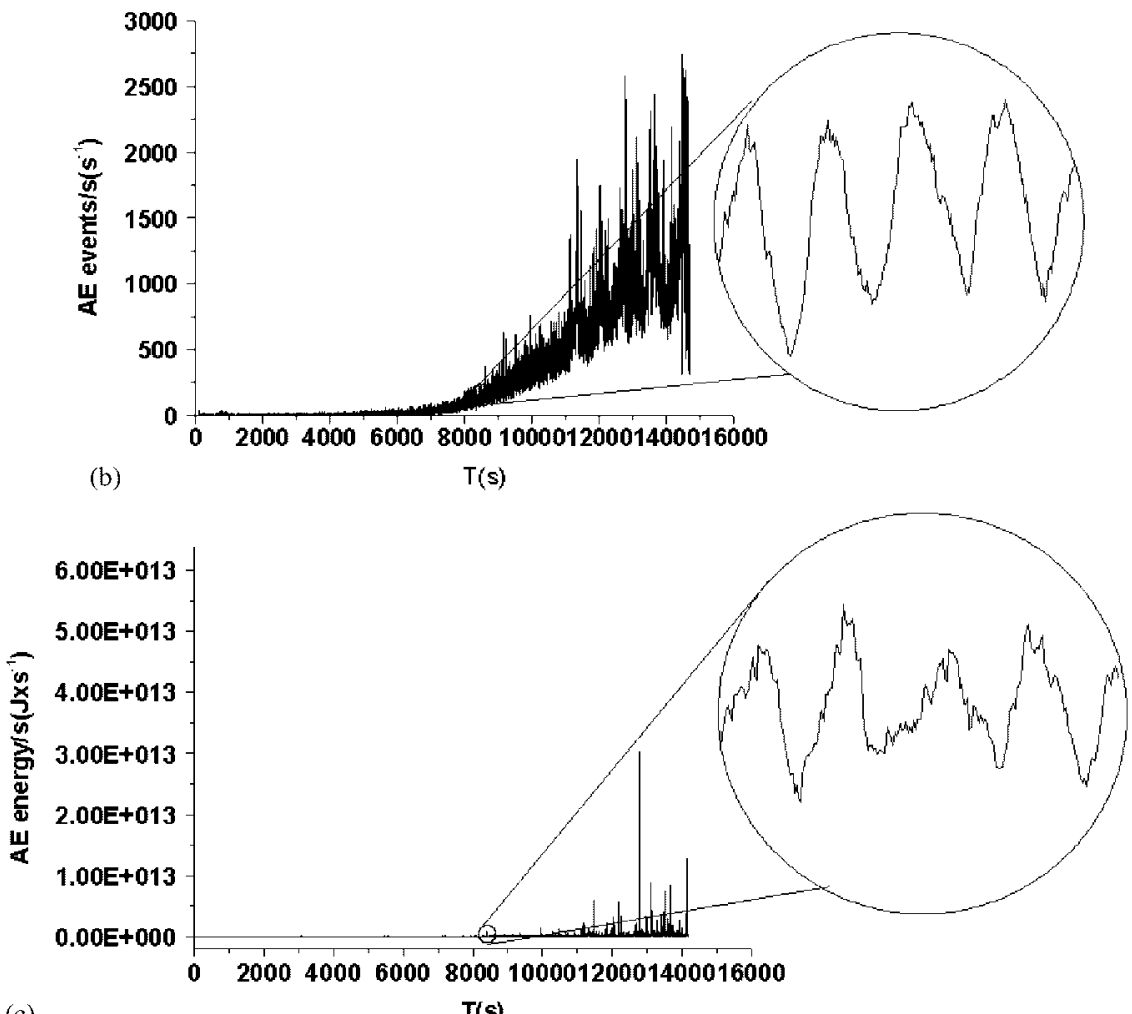

(c)

$T(s)$

Figure 5. The loading history and the corresponding experimental results for the specimen. (a) The loading history in the experiment. P1 is the axial load and P2 is the lateral load; and (b) the AE event rate versus time for the specimen; and (c) the AE energy rate versus time for the specimen. 


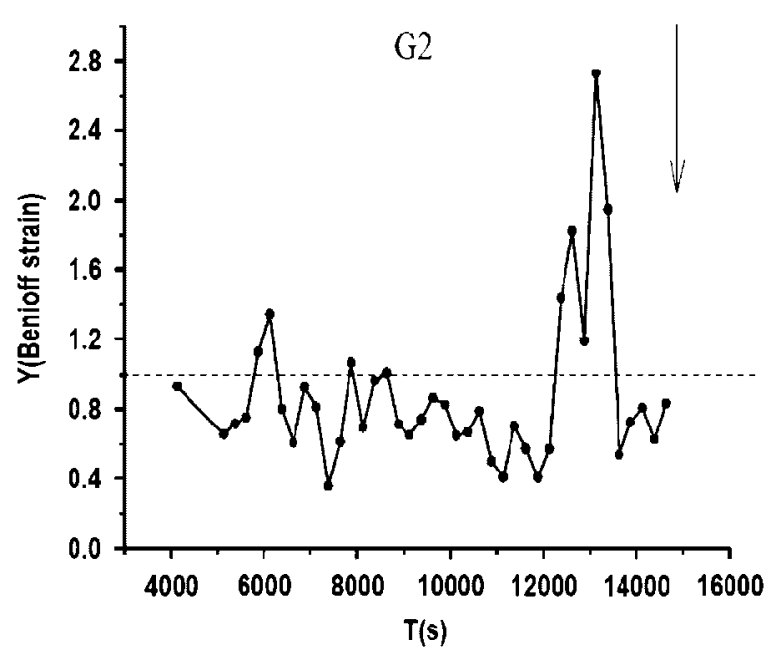

Figure 6. The curve of LURR during the rock fracture experiment of rock specimen with Benioff strain as response.

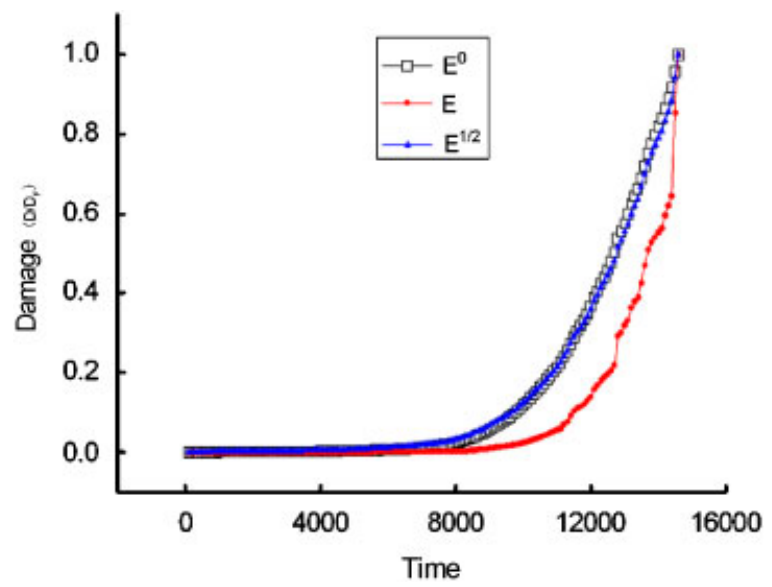

Figure 7. The evolution of damage defined with AE rate.

LURR evolution during the total experiment process, which can also reflect the damage evolution in the rock specimen to some extent. In Figure 6, when $t=13120 \mathrm{~s}$, the LURR value attained the maximum. Comparing Figure 6 with Figure 9, both LURR values experienced the process that abnormity appeared, rose to the peak value with relatively slow speed, then decreased sharply and failed or destabilized quickly, which indicates that the evolution of LURR defined with damage and strain is very similar to the one defined with Benioff strain as response rate. 


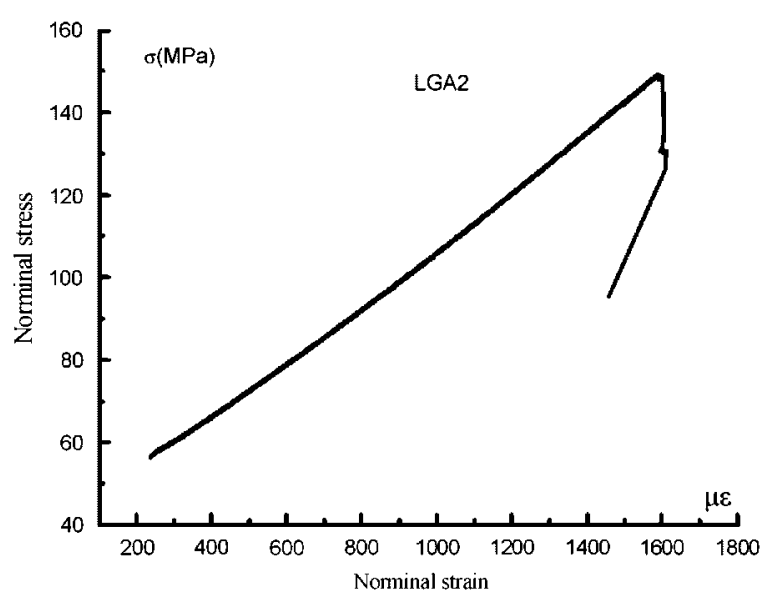

Figure 8. The curve of stress-strain in the experiment.

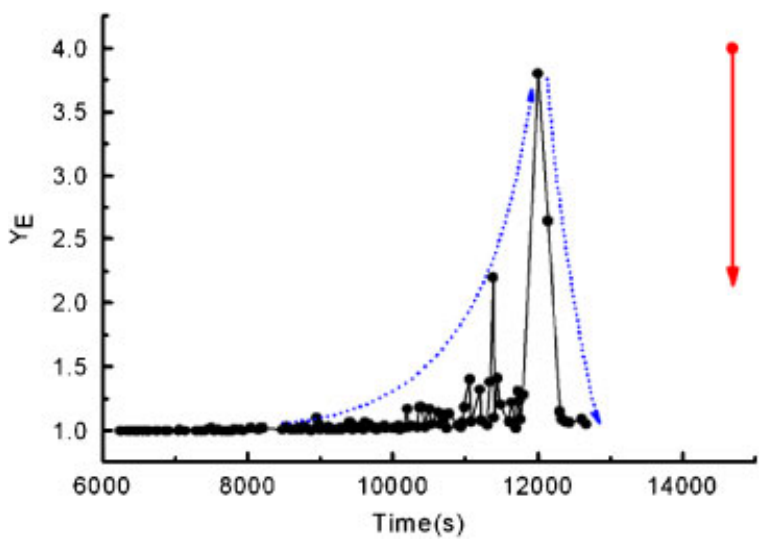

Figure 9. The curve of the new LURR versus time of the specimen (the arrow means the specimen got failed).

On the other hand, Figure 10 is the variation of LURR for the Loma Prieta earthquake which occurred in California on October 17, 1989, which is calculated with Benioff strain as the response rate by using seismic data in actual earthquake prediction. The tendency of LURR evolution in Figure 10 seems to be consistent with the ones shown in Figures 6 and 9, which may show the rationality of the LURR defined with Benioff strain as the response rate in the actual earthquake prediction. 


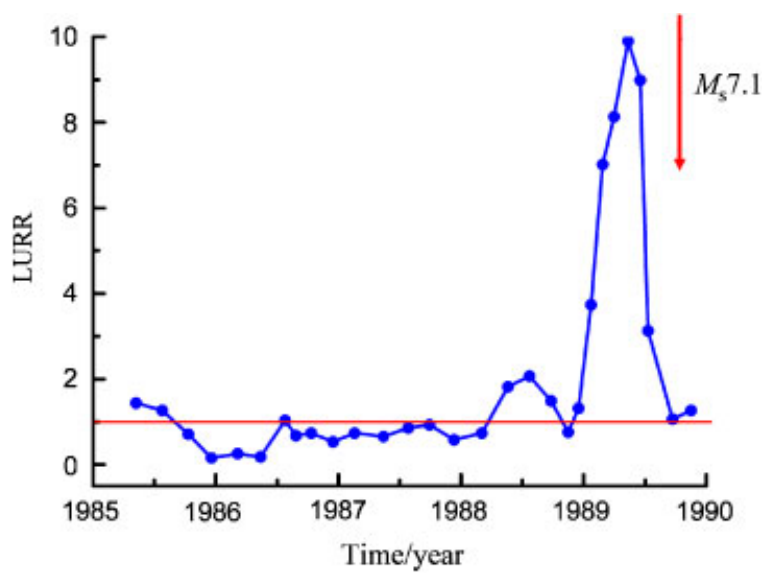

Figure 10. The variation of LURR for Loma Prieta earthquake occurred in California on October 17, 1989.

\section{DISCUSSION FOR APPLICATIONS OF THE RELATIONSHIP}

\section{Earthquake prediction}

The establishment of the relationship between LURR and $D$ is very significant, which provides the LURR theory with a more solid basis in physics and makes the LURR applied in damage analysis of materials from being qualitative to being quantitative. Hence, the relationship can instruct LURR to be used in earthquake prediction more precisely.

In order to investigate the seismicity in the China mainland, the tempo-spatial scanning of LURR from November 1, 2002 to June 30, 2008 has been conducted with 12, 15, 18, 24, 30, 36, 42 months as time window, 1 month as time step and the corresponding $R=70,100,200,300,400$, $500,600 \mathrm{~km}$ as scanning radius, respectively. Owing to the multi time windows and space windows, the tempo-spatial scanning needs plenty of computing power. Hence, adopting the technology of domain decomposition and parallelizing using MPI, a new parallel tempo-spatial scanning program was used in the computing [32], which was carried out by Super Computer Deep-Comp 6800 of the Super Computing Center of the Chinese Academy of Science. Limited by the paper length, we only show one result with $R=300 \mathrm{~km}$ as scanning radius in every 4 months, Figure 11 is the evolution of the anomaly LURR regions in time order. The notes for every result like 2002.11.1-2004.10.31, 0-5.0, 0.25, R300, 95, 1.0, where 2002.11.1-2004.10.31 means the begin date and end date of the time window, 0-5.0 means the magnitude threshold, 0.25 means the moving step length in both the latitudinal and longitudinal directions, R300 means the radius of circle region is $300 \mathrm{~km}, 95$ means the confidence is 0.95 , and 1.0 means the critical LURR value which corresponds to a neutral state between 'safety' and 'danger' of the seismicity.

From Figure 11, we can find that the anomaly LURR region appears along the Longmen Shan belt in the time window with October 31, 2004 as end date, and the anomaly area gets larger, about 

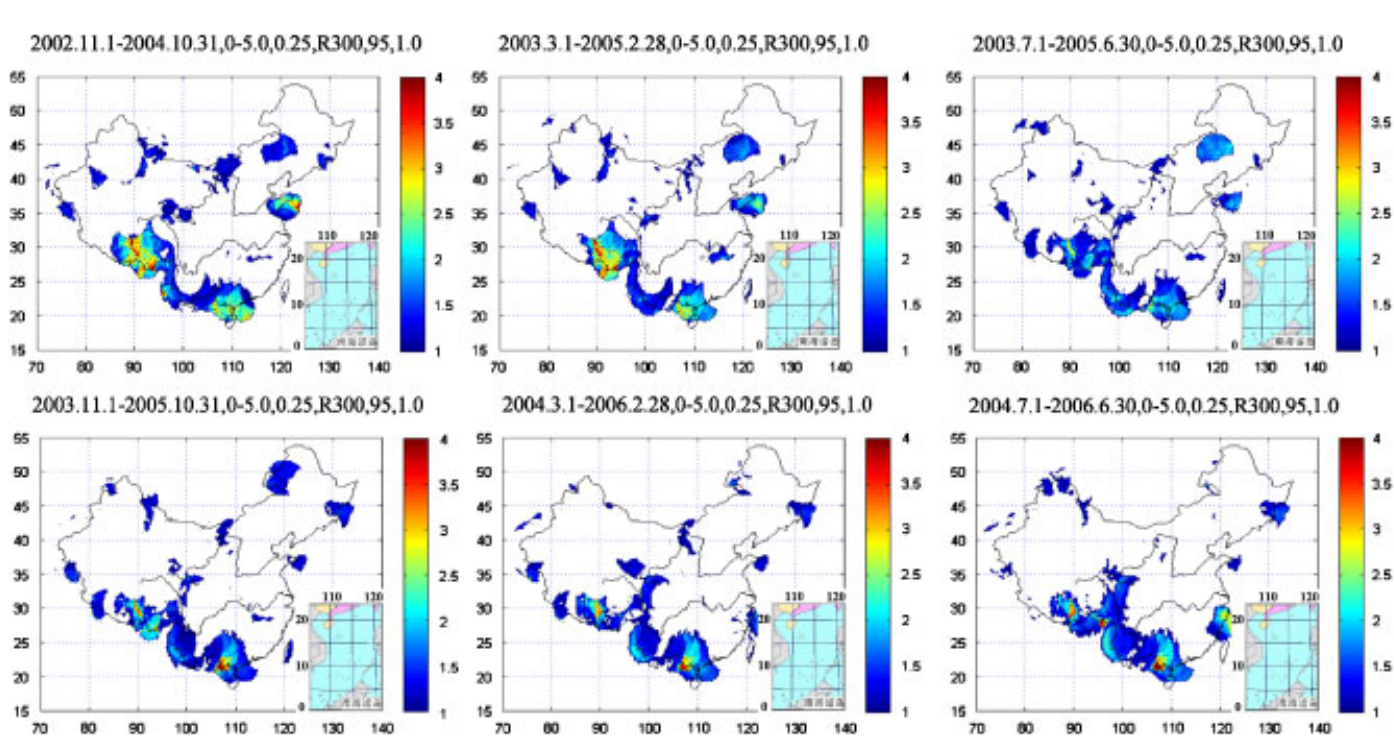

2004.7.1-2006.6.30,0-5.0,0.25,R300,95,1.0
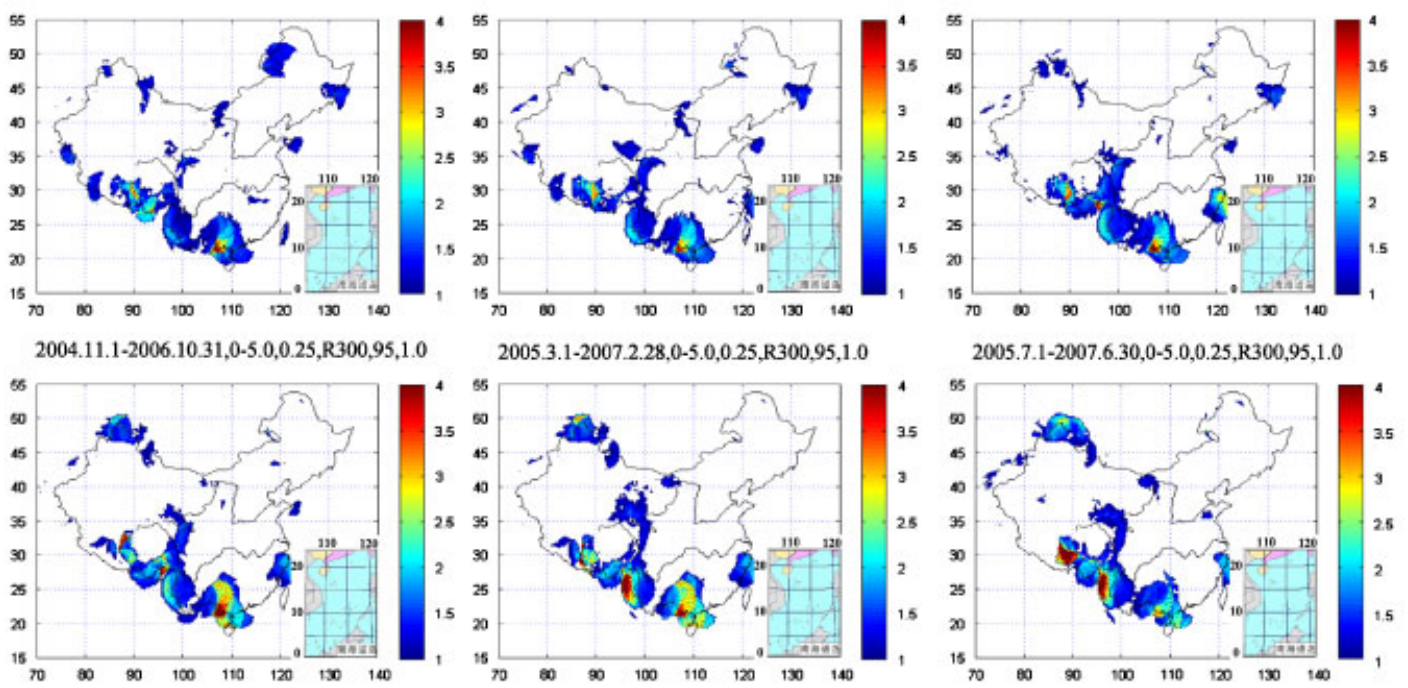

2005.11.1-2007.10.31,0-5.0,0.25,R300,95,1.0
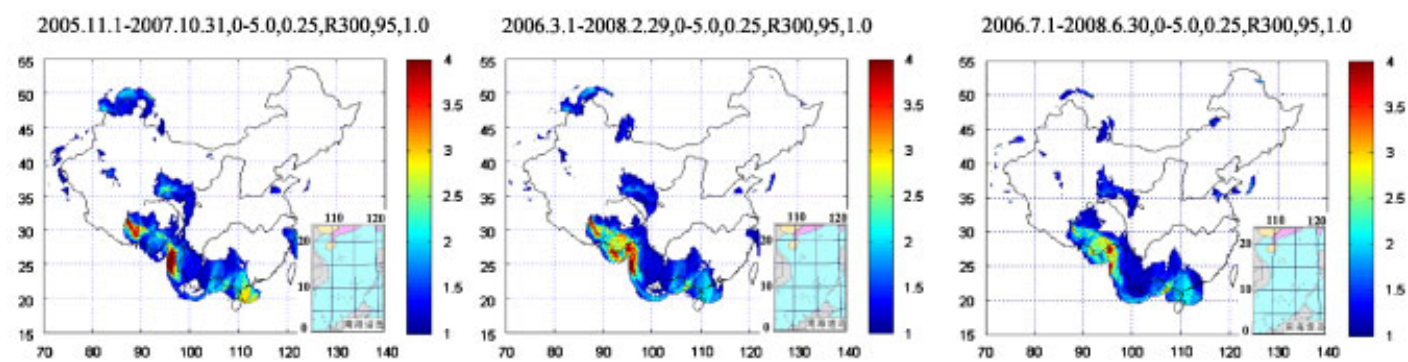

Figure 11. The temporal-spatial evolution of the anomaly LURR regions in China mainland.

up to June 30, 2006 when the area reaches the maximum, finally becoming smaller and smaller versus time, by the time of February 29, 2008, when the anomaly disappears. On May 12, 2008, a magnitude 8.0 earthquake, namely the Wenchuan earthquake occurred in the Longmen Shan belt. The evolution of the LURR in the Longmen Shan belt describes the seismogenious process of the Wenchuan earthquake clearly and completely. 


\section{Damage evaluation}

The relationship between LURR and $D$ not only provides the LURR theory with a more solid basis in physics, but may also give a new approach to the health assessment of large-scale structures and prediction of engineering catastrophic failure [33]. Some equations are indispensable in solving traditional mechanics problems such as governing equations, boundary, and initial conditions, but there is very little information about these equations to deal with disasters like earthquakes or to do health assessments of large-scale structures and ancient buildings. Fortunately, we can get the response of the structure by loading and unloading experiments, taking bridges, for example, loading and unloading can be achieved whether there are vehicles on the bridge or not. If the LURR value is obtained by experiments, the damage value can be calculated in terms of Equation (14). Furthermore, we can assess the health of the structure according to the damage value.

The process is introduced in detail as follows:

$$
Y_{\exp }=\left(\frac{\Delta R}{\Delta P}\right)_{+} /\left(\frac{\Delta R}{\Delta P}\right)_{-}
$$

where $\Delta P$ is the increment of the load in the experiment, $\Delta R$ is the corresponding response of the $\Delta P, R$ can be the displacement or strain etc. $Y_{\exp }$ is the LURR value in the experiment, according to the formula in Equation (14), the damage value can be conducted as $D=1-\exp \left(m\left(1-Y_{\exp }\right) / Y_{\exp }\right)$, while the damage value can reflect the health extent of the structure. Hence, LURR method may be used for health assessment of large-scale structures. An intensive study of this application will be performed by means of international cooperation with researchers from Naples University, Italy in the future.

\section{CONCLUSION}

The LURR method is being proposed for more than 20 years and some success in earthquake prediction has been achieved. Earlier, the larger LURR value meant the more severely the material is damaged, namely that LURR describes damaged materials qualitatively. Now, the relationship between LURR and $D$ is set up, which makes LURR to be applied in damage analysis for materials quantitatively. From the comparison of the LURR curves, we find that the LURR curves defined with Benioff strain as the response rate and with damage and strain as responses are very similar in trend and also validate the LURR defined with Benioff strain as response rate in the actual earthquake prediction is rational. Hence, the establishment of the relationship between LURR and $D$ is very significant, which not only provides a more solid basis to study the damage evolution of materials utilizing LURR method, but may also give a new approach to the health assessment of large-scale structures and prediction of engineering catastrophic failure.

The applications of the relationship between LURR and $D$ in earthquake prediction and damage evaluation or 'healthy-diagnoses' of large-scale engineering structures will be new projects for us to study in the future. 


\section{ACKNOWLEDGEMENTS}

The authors gratefully acknowledge the supports from the Special Funds for Major State Basic Research Programs under Grant No. 2004CB418406, NSFC under No. 40704007 and 10721202, the Ministry of Science and Technology of China (Grant No. 2005DKA64003). The authors also appreciate the help from Prof. Chi Xuebin, Prof. Lu Zhonghua, Dr Feng Yangde of the Super Computing Center of Chinese Academy of Sciences, and thanks them a lot.

\section{REFERENCES}

1. Yin XC. A new approach to earthquake prediction. Earthquake Research in China 1987; 3(1):1-7 (in Chinese with English abstract).

2. Yin XC, Yin C. The precursor of instability for nonlinear systems and its application to earthquake prediction. Science in China 1991; 34:977-986.

3. Yin XC, Chen XZ, Song ZP. The load/unload response ratio (LURR) theory and its application to earthquake prediction. Journal of Earthquake Prediction Research 1994; 3(3):325-333.

4. Yin XC, Chen XZ, Song ZP, Yin C. A new approach to earthquake prediction-the load/unload response ratio (LURR) theory. Pure and Applied Geophysics 1995; 145(3/4):701-715.

5. Yin XC, Chen XC, Song ZP, Wang YC. The temporal variation of LURR in Kanto and other regions of Japan and its application to earthquake prediction. Earthquake Research in China 1996; 10(4):381-385.

6. Yin XC, Wang YC, Peng KY, Bai YL, Wang HT, Yin XF. Development of a new approach to earthquake prediction: Load/unload response ratio (LURR) theory. Pure and Applied Geophysics 2000; 157(11-12):2365-2383.

7. Zhang HH, Yin XC, Liang NG. The spatial variation of LURR and seismic tendency in western United States. Earthquake Research in China 2005; 19(3):338-345.

8. Zhang LP, Yin XC, Liang NG. Application of load/unload response ratio in study of seismicity in the region of Iran. Earthquake Research in China 2007; 21(2):147-155.

9. Yin XC, Mora P, Peng KY, Wang YC, Weatherly D. Load-unload response ratio and accelerating moment/energy release critical region scaling and earthquake prediction. Pure and Applied Geophysics 2002; 159(9):2511-2523.

10. Yin XC, Yu HZ, Kukshenko V, Xu ZY, Wu ZS, Li M, Peng KY, Elizarov S, Li Q. Load-unload response ratio (LURR), accelerating energy release (AER) and state vector evolution as precursors to failure of rock specimens. Pure and Applied Geophysics 2004; 161(11-12):2405-2416.

11. Yin XC, Zhang LP, Zhang HH, Yin C, Wang YC, Zhang YX, Peng KY, Wang HT, Song ZP, Yu HZ, Zhuang JC. LURR's twenty years and its perspective. Pure and Applied Geophysics 2006; 163(11-12):2317-2341.

12. Yin XC, Zhang LP, Zhang YX, Peng KY, Wang HT, Song ZP, Yu HZ, Zhang HH, Yin C, Wang YC. The newest development of load/unload response ratio (LURR). Pure and Applied Geophysics 2008; 165(3-4):711-722.

13. Jiang T, Ma S, Xu B, Ma J. Study on laws of load-unload response of slope under seismic load. Chinese Journal of Rock Mechanics and Engineering 2004; 23(22):3803-3807 (in Chinese with English abstract).

14. He KQ, Zhou DY, Wang SJ. Features of load-unload response ratio and its significance in prediction of colluvial landside by rainfall. Chinese Journal of Rock Mechanics and Engineering 2004; 23(16):2665-2670.

15. Zhang WJ, Chen YM, Zhan LT. Loading/unloading response ratio (LURR) theory applied in predicting deep-seated landslides triggering. Engineering Geology 2006; 82:234-240.

16. Kachanov LM. Introduction to Continuum Damage Mechanics. Martinus Nijhoff: Dordrecht, 1986.

17. Lemaitre J. A Course on Damage Mechanics. Springer: Berlin, Heidelberg, 1992.

18. Lyakhovsky V, Ben-Zion Y, Agnon A. Distributed damage, faulting, and friction. Journal of Geophysical Research 1997; 102:27635-27649.

19. Lyakhovsky V, Reches Z, Weinberger R, Scott TE. Nonlinear elastic behavior of damaged rocks. Geophysical Journal International 1997; 130:157-166.

20. Zhang LP, Yin XC, Liang NG. Preliminary study on damage-healing model under earthquake. Chinese Journal of Rock Mechanics and Engineering 2009; 27(supp. 2):3956-3962 (in Chinese with English abstract).

21. Bai YL, Xia MF, Ke FJ, Li HL. Damage field equation and criterion for damage localization. Rheology of Bodies with Defects. Kluwer Academic Publishers: Dordrecht, 1998; 55-66.

22. Wei YJ, Xia MF, Ke FJ, Yin XC, Bai YL. Evolution induced catastrophe and its predictability. Pure and Applied Geophysics 2000; 157(11-12):1945-1957.

23. Weibull W. A statistical distribution function of wide applicability. Journal of Applied Mechanics 1951; 18:293-297.

24. Xu XH, Ma SP, Xia MF, Ke FJ, Bai YL. Damage evaluation and damage localization of rock. Theoretical and Applied Fracture Mechanics 2004; 42:131-138. 
25. Zhang HH, Yan YD, Yu HZ, Yin XC. Acoustic emission experiment research of large-scaled rock failure under cycling load-fracture precursor of rock. Chinese Journal of Rock Mechanics and Engineering 2004; 23(21):3621-3628 (in Chinese with English abstract).

26. Zhang HH, Yin XC, Liang NG, Li SY, Yu HZ, Wang YC, Yin C, Kukshenko V, Tomiline N, Elizarov S. Experimental study of rock precursor using simulated tide stress-load/unload response ratio (LURR) and accelerating energy release (AER). Chinese Journal of Rock Mechanics and Engineering 2005; 24(17):3172-3179 (in Chinese with English abstract).

27. Zhang HH, Yin XC, Liang NG, Yu HZ, Li SY, Wang YC, Yin C, Kukshenko V, Tomiline N, Elizarov S. Acoustic emission experiments of rock failure under load simulating the hypocenter condition. Pure and Applied Geophysics 2006; 163(11-12):2389-2406.

28. Zhang HH. Prediction of Catastrophic failure in heterogeneous brittle media-Study and practice of load/unload response ratio (LURR). PhD Thesis of Institute of Mechanics, CAS, 2006.

29. Bai YL, Xia MF, Ke FJ, Lu CS, Ling Z. Analysis and simulation of evolution induced catastrophe. Chinese Physics Letters 1993; 10(3):155-158.

30. Bai YL, Lu CS, Ke FJ, Xia MF. Evolution induced catastrophe. Physics Letters A 1994; 185(2):196-200.

31. Bai YL, Wang HY, Xia MF, Ke FJ. Statistical mesomechanics of solid, linking coupled multiple space and time scales. Applied Mechanics Reviews 2005; 58(6):372-388.

32. Feng YD, Chi XB, Wang W, Chen J, Yin XC. Fast computing for LURR of earthquake prediction. Pure and Applied Geophysics 2008; 165(3-4):749-759.

33. Zhang LP, Yin XC, Liang NG. Study on relation between load/unload response ratio and damage variable. Chinese Journal of Rock Mechanics and Engineering 2008; 27(9):1874-1881 (in Chinese with English abstract). 